\title{
Perbedaan Penyuluhan Kesehatan Gigi Menggunakan Media Gambar dengan Video dalam Meningkatkan Perilaku Menyikat Gigi pada Anak Tunarungu di SLB Negeri 1 Kota Jambi
}

\author{
Differences in Dental Health Extension Using Media Images with Videos \\ in Improving Tooth Brushing Behavior in Deaf Children in State SLB 1 in \\ Jambi City
}

\author{
Ervon Veriza $^{1}$, S. Riyadi ${ }^{1}$, W. Seisaria ${ }^{1}$ \\ ${ }^{1}$ Politeknik Kesehatan, Jambi, Indonesia \\ *Korespondensi penulis: ervonveriza@gmail.com
}

Penyerahan: 21-01-2020, Perbaikan: 24-10-2020, Diterima: 23-10-2020

\begin{abstract}
Hearing limitations in deaf children result in a lack of information obtained especially on how to maintain dental and oral health. Learning method is a tool that can help the teaching and learning process and serves to clarify the meaning of the message delivered. The purpose of the study was to determine the differences in dental health counseling using picture and video media in improving tooth brushing behavior in deaf children in Jambi City SLB 1 in 2019. This study used a Pre-Experimental Designs research design with a One-Shot Case Study design. The sampling technique used was purposive sampling, namely selecting samples representing the inclusion criteria of 22 respondents. The results showed that the average score of deaf teeth brushing behavior after being given counseling with picture media was 9.45 and the average score after being given counseling with video media was 6.36, there were significant differences between counseling using media images and videos in improve tooth brushing behavior in deaf children (sig value $=0.001$ ). Researchers advise deaf children to practice and apply how to brush their teeth properly in their daily lives.
\end{abstract}

Keywords: Counseling, Media, Images, Videos, Behavior, Brushing Teeth, Deaf.

\begin{abstract}
Abstrak
Keterbatasan pendengaran pada anak tunarungu mengakibatkan kurangnya informasi yang didapatkan terutama mengenai cara menjaga kesehatan gigi dan mulut. Metode pembelajaran merupakan alat yang dapat membantu proses belajar mengajar dan berfungsi untuk memperjelas makna pesan yang disampaikan. Tujuan penelitian adalah untuk mengetahui perbedaan penyuluhan kesehatan gigi menggunakan media gambar dengan video dalam meningkatkan perilaku menyikat gigi pada anak tunarungu di SLB Negeri 1 Kota Jambi Tahun 2019. Penelitian ini menggunakan desain penelitian Pre-Experimental Designs dengan rancangan One-Shot Case Study. Teknik pengambilan sampel yang digunakan adalah purposive sampling yaitu memilih sampel yang mewakili kriteria inklusi sebanyak 22 responden. Hasil penelitian didapatkan rata-rata skor perilaku menyikat gigi anak tunarungu sesudah diberikan penyuluhan dengan media gambar yaitu 9,45 dan ratarata skor sesudah diberikan penyuluhan dengan media video yaitu 6,36, ada perbedaan yang signifikan antara penyuluhan menggunakan media gambar dan video dalam meningkatkan perilaku menyikat gigi pada anak tunarungu (nilai sig $=0,001$ ). Peneliti menyarankan kepada anak tunarungu untuk mempraktikkan dan menerapkan bagaimana cara menyikat gigi yang benar di kehidupan sehari-hari.
\end{abstract}

Kata Kunci: Penyuluhan, Media, Gambar, Video, Perilaku, Menyikat Gigi, Tunarungu.

Jurnal Dunia Kesmas, Vol. 9 No. 4, Oktober 2020, hal. 457-462

ISSN 2301-6604 (Print), ISSN 2549-3485 (Online)

http://ejurnalmalahayati.ac.id/index.php/duniakesmas/index 


\section{PENDAHULUAN}

Tunarungu atau anak dengan ganguan pendengaran adalah anak anak yang mengalami gangguan pendengaran dengan derajat pendengaran yang bervariasi. Dikatakan sangat ringan ketika derajat pendengarannya antara $27 \mathrm{~dB}-40 \mathrm{~dB}$, lalu $41 \mathrm{~dB}-55 \mathrm{~dB}$ dikatakan ringan, 56dB-70dB dikatakan sedang, 71dB90dB dikatakan berat, dan 91 keatas dikatakan tuli (Widijati, 2018). Keterbatasan pendengaran pada anak tunarungu mengakibatkan kurangnya informasi yang didapatkan, termasuk mengenai kesehatan gigi dan mulut. Berdasarkan hal tersebut kelompok tunarungu dinilai sebagai kelompok yang lebih berisiko terkena karies dibandingkan kelompok tidak tunarungu (Widasari, 2010).

Kemampuan menggosok gigi secara baik dan benar merupakan faktor yang cukup penting untuk perawatan kesehatan gigi dan mulut. Keberhasilan menggosok gigi juga dipengaruhi oleh faktor penggunaan alat, metode menggosok gigi, serta frekuensi dan waktu menggosok gigi yang tepat (Houwink, 1994, cit., Budiharto, 2013). Berdasarkan hasil laporan Riset Kesehatan Dasar 2018 menunjukkan bahwa perilaku menyikat gigi setiap hari sebanyak $94,7 \%$ dan waktu menyikat gigi yang benar $2,8 \%$. Untuk perilaku menyikat gigi penduduk Provinsi Jambi yang mempunyai kebiasaan menyikat gigi setiap hari $96,4 \%$ dan waktu menyikat gigi yang benar $1,0 \%$ (Kemenkes RI, 2018). Metode pembelajaran merupakan alat yang dapat membantu proses belajar mengajar dan berfungsi untuk memperjelas makna pesan yang disampaikan, sehingga dapat mencapai tujuan pembelajaran dengan lebih baik dan sempurna (Sutandi, 2013, cit., Putriani, 2016).

Berdasarkan hasil wawancara dari Kepala SLB Negeri 1Kota Jambi bahwa di SLB tersebut diperoleh informasi bahwa terdapat 67 murid tunarungu berkriteria ringan. Hasil survey awal pada 9 murid tunarungu di SLB tersebut, semuanya menggosok gigi dengan cara horizontal. Hal ini dikarenakan kurangnya kegiatan rutin menyikat gigi dan penyuluhan kesehatan gigi pada anak tunarungu. Wawancara juga dilakukan dengan salah satu guru mengatakan bahwa anak tunarungu lebih mengerti menggunakan media gambar, karena saat proses belajar mengajar guru menggunakan metode pembelajaran dengan media gambar dan wujud asli dari suatu benda. Sedangkan media video jarang digunakan karena guru kurang mengerti cara menggunakan laptop untuk menayangkan video dan keterbatasan adanya infokus.

Berdasarkan informasi diatas, maka perlu adanya suatu upaya untuk mengatasi permasalahan cara menggosok gigi, agar anak tunarungu dapat menyikat gigi dengan baik dan benar. Dari permasalahan itu penulis tertarik untuk meneliti perbedaan penyuluhan kesehatan gigi menggunakan media gambar dengan video dalam meningkatkan perilaku menyikat gigi pada anak tunarungu di SLB Negeri 1 Kota Jambi Tahun 2019.

\section{METODE}

Penelitian ini dilakukan untuk mengetahui perbedaan penyuluhan kesehatan gigi menggunakan media gambar dengan video dalam meningkatkan perilaku menyikat gigi pada anak tunarungu di SLB Negeri 1 Kota Jambi Tahun 2019 dengan total populasi berjumlah 43 orang. Penentuan sampel dilakukan dengan Purposive Sampling, sebanyak 22 responden. Penelitian ini menggunakan desain penelitian PreExperimental Designs dengan rancangan One-Shot Case Study. Variabel penelitian ini adalah perilaku menyikat gigi yang diukur dengan instrument penelitian berupa lembar 
observasi perilaku menyikat gigi dan dianalisis menggunakan uji beda dua independen sample t-tes.

HASIL

Tabel 1. Distribusi Responden Berdasarkan Jenis Kelamin

\begin{tabular}{lcccccc}
\hline \multirow{2}{*}{ Variabel } & \multicolumn{4}{c}{ Jenis Kelamin } & \multirow{2}{*}{ Jumlah } \\
\cline { 2 - 6 } & Laki-laki & \multicolumn{2}{c}{ Perempuan } & \\
\cline { 2 - 6 } & $\mathbf{n}$ & $\mathbf{\%}$ & $\mathbf{n}$ & $\mathbf{\%}$ & $\mathbf{n}$ & $\mathbf{\%}$ \\
\hline Penyuluhan Media Gambar & 8 & 72,7 & 3 & 27,3 & 11 & 100 \\
\hline Penyuluhan Media Video & 4 & 36,4 & 7 & 63,6 & 11 & 100 \\
\hline
\end{tabular}

Berdasarkan tabel 1, diketahui jenis kelamin laki-laki pada anak tunarungu yang diberikan penyuluhan menggunakan media gambar di SLB Negeri 1 Kota Jambi paling banyak yaitu 8 orang $(72,7 \%)$, sedangkan penyuluhan menggunakan media video paling banyak jenis kelamin perempuan yaitu 7 orang $(63,6 \%)$.

Tabel 2. Distribusi Rata-Rata Skor Perilaku Menyikat Gigi

\begin{tabular}{|c|c|c|c|c|}
\hline \multirow{2}{*}{ Variabel } & \multirow{2}{*}{$\mathbf{n}$} & \multicolumn{2}{|c|}{ Skor } & \multirow{2}{*}{ Mean } \\
\hline & & Terendah & Tertinggi & \\
\hline Penyuluhan Media Gambar & 11 & 6 & 12 & 9,45 \\
\hline Penyuluhan Media Video & 11 & 4 & 10 & 6,36 \\
\hline
\end{tabular}

Berdasarkan tabel 2, diketahui bahwa rata-rata skor perilaku menyikat gigi pada anak tunarungu di SLB Negeri 1 Kota Jambi tahun 2019 sesudah diberikan penyuluhan dengan media gambar adalah 9,45, sedangkan penyuluhan menggunakan media video rata-rata skor perilaku menyikat gigi adalah
6,36. Data diuji normalitas terlebih dahulu untuk mengetahui data berdistribusi normal atau tidak. Uji normalitas yang digunakan adalah uji Shapiro Wilk karena jumlah sampel kurang dari 50 responden dan uji bersifat normal apabila $p$ value > 0,05 (Herawati, 2016).

Tabel 3. Hasil Uji Normalitas

\begin{tabular}{lccc}
\hline \multirow{2}{*}{ Variabel } & \multicolumn{3}{c}{ Shapiro - Wilk } \\
\cline { 2 - 4 } & $\mathbf{n}$ & Sig & Keterangan \\
\hline Penyuluhan dengan Media Gambar & 11 & 0,410 & Normal \\
\hline Penyuluhan dengan Media Video & 11 & 0,609 & Normal \\
\hline
\end{tabular}

Berdasarkan tabel 3, diketahui bahwa hasil uji normalitas pada penyuluhan menggunakan media gambar diperoleh nilai Sig $=0,410$ dan penyuluhan menggunakan media video diperoleh nilai Sig $=0,609$, maka dapat disimpulkan bahwa kedua variabel memiliki data bersifat normal. Berdasarkan tabel 4, diketahui bahwa skor rata-rata penyuluhan menggunakan media gambar sebesar 9,45, sedangkan penyuluhan menggunakan media video sebesar 6,36, hasil uji statistik diperoleh nilai Sig $=0,001$ ( $p$ value $<$ $0,05)$, maka dapat disimpulkan bahwa ada perbedaan yang signifikan antara penyuluhan menggunakan media gambar dengan video, dengan demikian gagal menolak hipotesis alternatif. 
Tabel 4. Perbedaan Penyuluhan dengan Media Gambar dan Media Video

\begin{tabular}{lcccc}
\hline \multicolumn{1}{c}{ Perilaku Menyikat Gigi } & Mean & df & P-Value \\
\cline { 1 - 2 } Penyuluhan dengan Media Gambar & 9,45 & \multirow{2}{*}{20} & \multirow{2}{*}{0,001} \\
\hline Penyuluhan dengan Media Video & 6,36 & & \\
\hline
\end{tabular}

PEMBAHASAN

Perilaku Menyikat Gigi Anak Tunarungu Sesudah Diberikan Penyuluhan Menggunakan Media Gambar

Berdasarkan tabel 2 dimana responden berjumlah 11 orang menunjukkan bahwa skor perilaku menyikat gigi pada anak tunarungu sesudah diberikan penyuluhan dengan media gambar di SLB Negeri 1 Kota Jambi yang memiliki skor terendah yaitu 6, dan skor tertinggi yaitu 12, sehingga diperoleh nilai rata-ratanya adalah 9,45. Hal ini kemungkinan disebabkan karena anak tunarungu atau anak yang memiliki gangguan pada fungsi pendengaran mampu belajar melalui media visual seperti gambar, terlebih gambar yang menarik. Media gambar bisa diamati dan dipahami sehingga dapat memudahkan anak tunarungu untuk mengingat apa yang disampaikan.

Faktor utama yang mempengaruhi kesehatan gigi dan mulut adalah perilaku. Perilaku yang dapat mempengaruhi penyakit gigi dan mulut adalah kurang mengetahui tentang cara menjaga kesehatan gigi dan mulut. Perilaku sangat dipengaruhi oleh pengetahuan. Perilaku yang didasari pengetahuan yang benar akan lebih bertahan lama daripada perilaku yang tidak didasari pengetahuan, termasuk pengetahuan tentang cara menjaga kesehatan gigi yang benar akan sangat berpengaruh terhadap kejadian karies. Upaya untuk meningkatkan pengetahuan dan perilaku adalah dengan penyuluhan kesehatan. Penyuluhan dengan berbagai sasaran lebih ditekankan pada kelompok rentan anak sekolah (Supariani, 2016). Penelitian ini sejalan dengan Kantohe, dkk (2016), menunjukkan bahwa rata-rata skor post-test menggunakan media flipchart sebesar 86,25 .

\section{Perilaku Menyikat Gigi Anak Tunarungu Sesudah Diberikan Penyuluhan Menggunakan Media Video}

Berdasarkan tabel 2 dimana responden berjumlah 11 orang menunjukkan bahwa skor perilaku menyikat gigi pada anak tunarungu sesudah diberikan penyuluhan dengan media gambar di SLB Negeri 1 Kota Jambi yang memiliki skor terendah yaitu 4, dan skor tertinggi yaitu 10 , sehingga diperoleh nilai rata-ratanya adalah 6,36. Hal ini kemungkinan disebabkan karena media video bersifat satu arah dan mempunyai durasi waktu, sehingga anak harus menyimak dan memperhatikan informasi yang disampaikan agar tidak ketinggalan.

Penyuluhan dengan media video merupakan media yang sesuai dengan karakteristik anak SD yang sangat menyukai kesenangan dan keinginan mengetahui sesuatu yang baru (Edyati, 2014). Hasil penelitian Edyati (2014) di Yogyakarta mengenai pengetahuan setelah dilakukan penyuluhan kesehatan dengan media video didapatkan kategori baik sebanyak 33 responden $(91,7 \%)$. Hasil ini juga sejalan dengan penelitian Supariani, dkk (2016) bahwa rata-rata tingkat pengetahuan siswa di Denpasar Timur setelah mendapatkan penyuluhan kesehatan gigi adalah 89,85 dengan kategori baik. 


\section{Perbedaan Penyuluhan Kesehatan Gigi Menggunakan Media Gambar dengan Video dalam Meningkatkan Perilaku Menyikat Gigi Pada Anak Tunarungu}

Berdasarkan tabel 4 bahwa penyuluhan kesehatan gigi dan mulut menggunakan media gambar dan video dalam meningkatkan perilaku menyikat gigi pada anak tunarungu diperoleh hasil uji 2 independent sample test dengan nilai $p$ value $=$ $0,001 \quad(\mathrm{p}<0,05)$, maka ada perbedaan yang signifikan antara penyuluhan menggunakan media gambar dengan video. Hal ini kemungkinan disebabkan karena media yang berbeda juga mempengaruhi tingkat pola pikir anak dalam memahami. Penelitian ini sejalan dengan penelitian Kantohe (2016), menunjukkan bahwa ada perbedaan yang bermakna antara penyuluhan kesehatan menggunakan media audio visual dan media cetak yaitu nilai $p$ value $0,009(<0,05)$.

Hasil

penelitian

ini

menunjukkan bahwa media gambar lebih efektif dari pada media video, kemungkinan disebabkan media gambar mampu memberikan waktu untuk anak dalam mencermati dan memahami, media gambar adalah media yang tepat untuk sasaran anak tunarungu, karena anak tunarungu mempunyai keterbatasan dalam pendengaran, sehingga dalam melakukan pembelajaran atau penyuluhan lebih ditekankan pada indera penglihatan. Sedangkan media video kemungkinan adanya kelemahan pada durasi pemutaran video yang dilakukan tanpa berhenti sehingga daya tangkap sasaran sangat berpengaruh terhadap pemahaman dan pengetahuan anak. Menurut Notoatmodjo (2003), pengetahuan merupakan hasil dari tahu, dan ini terjadi setelah orang melakukan penginderaan terhadap suatu objek tertentu. Penginderaan terjadi melalui pancaindra manusia, yakni indera penglihatan, pendengaran, penciuman, rasa, dan raba. Sebagian besar pengetahuan manusia diperoleh melalui mata dan telinga.

\section{KESIMPULAN}

Berdasarkan hasil penelitian yang telah dilakukan pada anak tunarungu di SLB Negeri 1 Kota Jambi Tahun 2019 dapat diambil kesimpulan sebagai berikut:

1. Rata-rata skor perilaku menyikat gigi anak tunarungu sesudah diberikan penyuluhan dengan media gambar didapatkan skor terendah adalah 6, dan skor tertinggi adalah 12, sehingga rata-rata skor adalah 9,45.

2. Rata-rata skor perilaku menyikat gigi anak tunarungu sesudah diberikan penyuluhan dengan media video didapatkan skor terendah adalah 4, dan skor tertinggi adalah 10, sehingga rata-rata skor adalah 6,36.

3. Ada perbedaan yang signifikan atau bermakna antara perilaku penyuluhan menggunakan media gambar dengan video dalam meningkatkan perilaku menyikat gigi pada anak tunarungu di SLB Negeri 1 Kota Jambi Tahun 2019 dengan nilai $p$ value sebesar $0,001(p<0,05)$.

\section{SARAN}

1. Disarankan kepada Instansi Dinas Kesehatan dapat membuat program pembinaan promosi kesehatan melalui penyuluhan kepada pihak sekolah agar meningkatkan derajat kesehatan dan pemeliharaan kesehatan khususnya kesehatan gigi dan mulut. 
2. Disarankan kepada Jurusan Keperawatan Gigi dapat dijadikan sebagai referensi dibidang keperawatan gigi untuk meningkatkan pengetahuan pada Anak Berkebutuhan Khusus dengan pemilihan media yang tepat.

3. Disarankan kepada murid SLB Negeri 1 dapat mempraktikkan dan menerapkan teknik menyikat gigi, waktu dan frekuensi yang tepat seperti menyikat gigi dua kali sehari pagi setelah sarapan dan malam sebelum tidur.

4. Disarankan kepada orang tua untuk lebih berperan aktif dalam memperhatikan kondisi gigi dan mulut anak di rumah dengan mengingatkan dan membiasakan menyikat gigi dengan waktu yang tepat.

5. Disarankan kepada peneliti selanjutnya untuk lebih mengembangkan penelitian tentang kesehatan gigi pada Anak Berkebutuhan Khusus.

\section{DAFTAR PUSTAKA}

Budiharto, 2013. Pengantar IImu Perilaku Kesehatan dan Pendidikan Kesehatan Gigi. Jakarta: Buku Kedokteran EGC.

Edyati, L, 2014. Pengaruh Penyuluhan Kesehatan dengan Media Video Terhadap Pengetahuan dan Sikap Personal Hygiene Siswa SD Negeri 1 Kulon Progo. Skripsi STIKES Aisyiyah Yogyakarta.

Herawati, L., Kadarusno, A, 2016. Uji Normalitas Data Kesehatan Menggunakan SPSS. Yogyakarta: Poltekkes Jogja Press.

Kantohe, Z., Wowor, V., Gunawan, P, 2016. Perbandingan
Efektivitas Pendidikan

Kesehatan Gigi

Menggunakan Media Video dan Flip Chart Terhadap Peningkatan Pengetahuan Kesehatan Gigi dan Mulut Anak. Jurnal Universitas Sam Ratulangi Mando. 4(2), 98.

Kemenkes RI, $2018 . \quad$ Laporan Nasional Riskesdas

2018. Badan Penelitian dan Pengembangan Kesehatan. Jakarta.

Notoatmodjo, 2003. Pendidikan dan Perilaku Kesehatan. Jakarta: Rineka Cipta.

Putriani, Gigi, 2016. Peningkatan Upaya Pembelajaran Bin Diri Menggosok Gigi Melalui Media Video Animasi Pada Anak Tunagrahita Kategori Sedang Kelas IV SDBL di SLB Negeri Pembina Yogyakarta. Skripsi Program Studi Pendidikan Luar Biasa Universitas Negeri Yogyakarta.

Supariani, N., Ratmini, N, 2016. Efektivitas Penyuluhan untuk Meningkatkan Pengetahuan Kesehatan Gigi dan Mulut Siswa Kelas V SDN 16 Kesiman Denpasar Timur. Jurnal Poltekkes Denpasar. 4(1), 36.

Widasari, D, 2010. Perbedaan Status Kesehatan Gigi Dan Mulut Pada Anak Tuna Rungu Dengan Anak Tidak Tuna Rungu Usia 6 Sampai 12 Tahun. Skripsi Fakultas Kedokteran Gigi Universitas Jember.

Widijati. U, 2018. Terapi Non Medis Bagi ADHD. Bumi Literasi. Yogyakarta 